\title{
Physical characterisations of a single-stage Kühni-type aqueous two-phase extraction column
}

\begin{abstract}
The main parameters which influence the behaviour of phase separation in a single-stage Kühni-type aqueous two-phase extraction column containing polyethylene (PEG) and dipotassium hydrogen phosphate were characterised. Two aqueous two-phase system (ATPS) composed of $12 \%(\mathrm{w} / \mathrm{w})$ PEG 1450 and $12 \%(\mathrm{w} / \mathrm{w})$ di-potassium hydrogen phosphate (designated as 12/12) and 12\% (w/w) PEG 1450 and $11 \%(\mathrm{w} / \mathrm{w})$ di-potassium hydrogen phosphate (designated as 12/11) were chosen in this study. The hold-up D increased with increasing impeller speeds and mobile phase flow rates. Phase separation for the 12/11 system was slower than that for the 12/12 system, which resulted in higher dispersed phase hold-up values for the 12/11 system. For 12/12 system, mass transfer of plasmid DNA (pDNA) from the dispersed mobile phase to the stationary phase increased rapidly with increasing impeller speeds of 130, 160 and $200 \mathrm{rpm}$ which was reflected in the decreased values for CT/CTo. The degree of back-mixing quantified by the axial dispersion coefficient Dax was estimated to be $2.7 \times 10-6 \mathrm{~m} 2 \mathrm{~s}-1$.
\end{abstract}

Keyword: Bioseparations, Aqueous two-phase system, Extraction, Precipitation, Physical 